\title{
ChemComm
}

\section{Boron-nitride and aluminum-nitride "Pringles" and flapping motion $\dagger$}

Cite this: Chem. Commun., 2014, 50,7444

Received 28th March 2014

Accepted 18th May 2014

DOI: $10.1039 / \mathrm{c} 4 \mathrm{cc} 02294 \mathrm{~g}$

www.rsc.org/chemcomm

\author{
Wei Fa, ${ }^{\star a b}$ Shuang Chen ${ }^{\mathrm{b}}$ and Xiao Cheng Zeng ${ }^{{ }^{\mathrm{b}}}$
}

\begin{abstract}
Motivated by the recent successful synthesis of a new nanocarbon, namely, a warped, double-concave graphene "Pringle" (Nat. Chem., 2013, 5, 739), we investigate properties of warped boron-nitride (BN) and aluminum-nitride (AIN) analogues, i.e., the non-planar $\mathrm{B}_{40} \mathrm{~N}_{40} \mathrm{H}_{30}$ and $\mathrm{Al}_{40} \mathrm{~N}_{40} \mathrm{H}_{30}$ "Pringles" using density functional theory (DFT) calculations. Particular attention is placed on the effect of non-hexagonal rings on the stability and physical properties of BN and AIN Pringles. We find that the warped BN and AIN Pringles with one pentagon and five heptagons are stable without imaginary frequencies. Both the warped $B_{40} \mathrm{~N}_{40} \mathrm{H}_{30}$ and $\mathrm{Al}_{40} \mathrm{~N}_{40} \mathrm{H}_{30}$ Pringles are expected to be flexible in solution as both can periodically change their shape in a dynamic "flapping" fashion due to their much lower activation barrier of racemization compared to that of the $\mathrm{C}_{80} \mathrm{H}_{30}$ counterpart. Since the warped $\mathrm{B}_{40} \mathrm{~N}_{40} \mathrm{H}_{30}$ possesses a smaller HOMO-LUMO gap than the planar $\mathrm{B}_{39} \mathrm{~N}_{39} \mathrm{H}_{30}$, it is expected that incorporating non-hexagonal ring defects by design can be an effective way to modify electronic properties of BN-based nanoplates.
\end{abstract}

The discovery of the $\mathrm{C}_{60}$ fullerene, ${ }^{1}$ carbon nanotubes ${ }^{2}$ as well as monolayer graphene ${ }^{3}$ has attracted tremendous interest in seeking new members in the nanocarbon family as well as low-dimensional nanomaterials of carbon analogues. Indeed, a variety of structure analogues of nanocarbons without containing carbon elements has been synthesized in the laboratory. Well-known examples are the boron-nitride (BN) nanomaterials which can be viewed as isoelectronic "cousins" to many nanocarbon allotropes. ${ }^{4-10}$ Unlike the covalent $\mathrm{C}-\mathrm{C}$ bonds, the partially ionic B- $\mathrm{N}$ bonds can significantly affect geometric and electronic structures of BN nanomaterials. For example, a BN monolayer is a wide direct bandgap semiconductor

\footnotetext{
${ }^{a}$ National Laboratory of Solid State Microstructures and Department of Physics, Nanjing University, Nanjing, 210093, China. E-mail: wfa@nju.edu.cn

${ }^{b}$ Department of Chemistry, University of Nebraska-Lincoln, Lincoln, Nebraska, 68588, USA. E-mail:xzeng1@unl.edu

$\dagger$ Electronic supplementary information (ESI) available: Computational details, different nanoplate isomers, vibrational analysis of the optimized structures, Cartesian coordinates, and Born-Oppenheimer molecular dynamics simulation of the racemization process of the $\mathrm{B}_{40} \mathrm{~N}_{40} \mathrm{H}_{30}$ nanoplate. See DOI: 10.1039/ c4cc02294g
}

while monolayer graphene is a semimetal with a zero bandgap. ${ }^{11-14}$ Note however that BN cages are structurally dissimilar to carbon fullerenes. This is because BN clusters with perfect BNBN alternation are energetically preferred due to less strain energy and aromatic destabilization. ${ }^{15,16}$

It is known that the presence of defects may induce notable changes in nanostructures, thereby modifying nanomaterials' physical properties. As an example, line defects in the hexagonal $\mathrm{BN}(h-\mathrm{BN})$ monolayer, characterized by boundaries between $f c c$ domains and a small population of $h c p$ domains, have been observed during the growth of $h-\mathrm{BN}$ on the Ni(111) surface. ${ }^{17}$ The existence of an extended line defect in a BN sheet presents a way to modify electronic or magnetic properties of the $\mathrm{BN}$ sheet for potential applications in nanoelectronics and spintronics. A recent theoretical study of line-defect-containing BN sheets, nanoribbons, and single-walled BN nanotubes shows that the bandgaps can be changed by the pentagon-octagon-pentagon line defects created by inserting $\mathrm{B}_{2}, \mathrm{~N}_{2}$, or $\mathrm{C}_{2}$ dimers. ${ }^{18}$ Yamijala and Pati found that electronic and magnetic properties of a $\mathrm{BN}$ nanoribbon can be modified by adding a number of (odd or even) pentagon-heptagon line defects at the ribbon edges. ${ }^{19}$ These studies suggest that controlled topological (non-hexagonal rings) defects can be useful to modulate electronic properties of $\mathrm{BN}$ nanostructures.

Very recently, a new carbon nanostructure belonging to the nanocarbon family, i.e., the first non-planar nanographene, has been reported. ${ }^{20}$ Kawasumi et al. successfully synthesized a grossly warped nanographene $\mathrm{C}_{80} \mathrm{H}_{30}$ having twenty-six polygons, among which five are heptagons and one is pentagon. The introduction of five heptagons not only causes the nanographene to warp but also alters its electronic and optical properties. This warped nanographene exhibits many unique features such as a facile bowl-to-bowl inversion of the central corannulene, a unique racemization pathway, as well as a larger gap ( $3.06 \mathrm{eV}$ ) between the highest occupied molecular orbital (HOMO) and the lowest unoccupied molecular orbital (LUMO). In view of many structural similarities between BN and carbon nanostructures, it is expected that the embedding of non-hexagonal rings into a BN nanoplate would provide a new member of BN nanostructures as well. Besides $\mathrm{BN}$, we also investigate a warped 
aluminium-nitride (AlN) nanoplate for the purpose of comparison. AlN nanomaterials are often used in deep ultraviolet optoelectronics, and as building blocks in new nanomaterials. ${ }^{21-24}$

We carry out a series of density functional theory (DFT) calculations to investigate the structural, electronic, and optical properties of the warped $\mathrm{BN}$ and $\mathrm{AlN}$ nanoplates. We show that the grossly warped nanostructures of $\mathrm{B}_{40} \mathrm{~N}_{40} \mathrm{H}_{30}$ and $\mathrm{Al}_{40} \mathrm{~N}_{40} \mathrm{H}_{30}$ with multiple odd-membered-ring defects are locally stable and their electronic and optical properties can be modified by the non-hexagonal ring defects. The warped $\mathrm{B}_{40} \mathrm{~N}_{40} \mathrm{H}_{30}$ exhibits a markedly reduced HOMO-LUMO gap and red-shifted optical absorption spectra compared to the planar $\mathrm{B}_{39} \mathrm{~N}_{39} \mathrm{H}_{30}$ with perfect BNBN alternation.

Geometry optimizations are performed using the B3LYP functional and the 6-31G(d) basis set. Computational details and validation of the computational methods are given in the $\mathrm{ESI} \dagger$ (Tables S1 and S2 and Fig. S1). The initial structures are constructed from the 26-ring $\mathrm{C}_{80} \mathrm{H}_{30}$ as a template. With five heptagons and one pentagon added in the nanoplates, the $\mathrm{B}-\mathrm{B}, \mathrm{Al}-\mathrm{Al}$, or $\mathrm{N}-\mathrm{N}$ bonds are formed at the pentagonal and heptagonal sites. Thus, there are at least six homonuclear bonds in the warped structure. The other sites exhibit alternate $\mathrm{B}-\mathrm{N}$ bonds.

First, various isomers of the $\mathrm{BN}$ and $\mathrm{AlN}$ nanoplates are examined (see ESI, $\dagger$ Fig. S2-S4) and the lowest-energy $\mathrm{B}_{40} \mathrm{~N}_{40} \mathrm{H}_{30}$ and $\mathrm{Al}_{40} \mathrm{~N}_{40} \mathrm{H}_{30}$ isomers are identified (see Fig. 1). Both lowest-energy nanostructures exhibit similar configurations with maximum 19 hexagons in an alternating BNBN (or AlNAlN) sequence. Other higher-energy isomers typically have less number of hexagons with BNBN (or AlNAIN) alternation. More specifically, the lowest-energy $\mathrm{B}_{40} \mathrm{~N}_{40} \mathrm{H}_{30}$ is $3.85 \mathrm{eV}$ lower in energy than the isomer with $18 \mathrm{BNBN}$ alternative hexagons, which can be viewed as exchanging a pair of $\mathrm{B}$
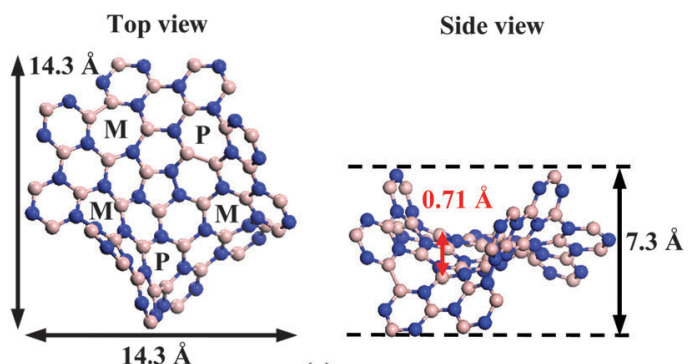

(a)
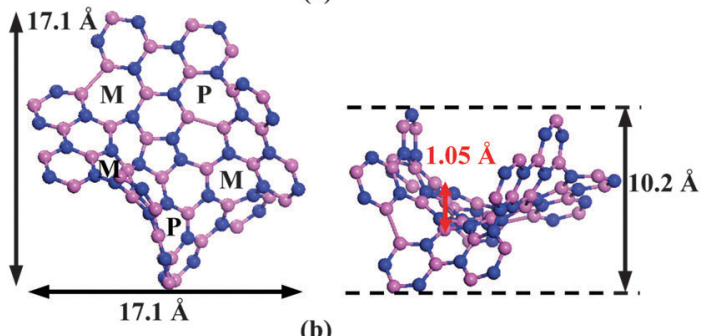

(b)

Fig. 1 Optimized warped structures of (a) $\mathrm{B}_{40} \mathrm{~N}_{40} \mathrm{H}_{30}$ and (b) $\mathrm{Al}_{40} \mathrm{~N}_{40} \mathrm{H}_{30}$ nanoplates. Top and side views are on the left and right panels, respectively. $\mathrm{B}, \mathrm{Al}$, and $\mathrm{N}$ atoms are represented by light pink, dark pink, and navy blue balls, respectively. All hydrogen atoms at the perimeter are omitted for clarity. $M$ represents a left-handed helix around the seven-membered ring, while $P$ denotes a right-handed helix. The bowl depth, labeled by red arrows, is calculated as an averaged depth between the centroid of the central pentagon and second-nearest neighboring atoms to the pentagonal vertices. and $\mathrm{N}$ atoms at the edge of the lowest-energy isomer $\mathrm{B}_{40} \mathrm{~N}_{40} \mathrm{H}_{30}$. This result confirms the previous theoretical prediction that the $\mathrm{B}-\mathrm{B}$ and $\mathrm{N}-\mathrm{N}$ bonds should be avoided as much as possible in BN clusters as they would result in much less stable isomers. ${ }^{15}$ Like the warped $\mathrm{C}_{80} \mathrm{H}_{30}$ with enantiomers of $M P M P M$ and PMPMP configurations, the presence of five helical hexa[7]circulene moieties, ${ }^{25}$ each with $M$ or $P$ chirality around the heptagon, also renders the lowest-energy structures having an isoenergetic enantiomer of PMPMP (see below). Computed vibrational spectra of the warped $\mathrm{B}_{40} \mathrm{~N}_{40} \mathrm{H}_{30}$ and $\mathrm{Al}_{40} \mathrm{~N}_{40} \mathrm{H}_{30}$ have a frequency range of 10.6-3622.2 and 3.5-3561.7 $\mathrm{cm}^{-1}$, respectively, and the spectra exhibit a strong peak at 1440 and $930 \mathrm{~cm}^{-1}$, respectively. These strong peaks can be used as a fingerprint to determine the warped nanostructures in future experiments. Note that the highest vibrational frequency of the warped $\mathrm{B}_{40} \mathrm{~N}_{40} \mathrm{H}_{30}$ is higher than that of the $\mathrm{Al}_{40} \mathrm{~N}_{40} \mathrm{H}_{30}$ or $\mathrm{C}_{80} \mathrm{H}_{30}\left(3242.3 \mathrm{~cm}^{-1}\right)$, reflecting stronger $\mathrm{B}-\mathrm{N}$ bonds than $\mathrm{Al}-\mathrm{N}$ bonds and $\mathrm{C}-\mathrm{C}$ bonds (see ESI, $\dagger$ Fig. S5).

We find that the warped $\mathrm{B}_{40} \mathrm{~N}_{40} \mathrm{H}_{30}$ and $\mathrm{Al}_{40} \mathrm{~N}_{40} \mathrm{H}_{30}$ not only can flip back and forth between two different conformers through bowlto-bowl inversion, but also change between two enantiomers through a racemization pathway (see Fig. 2 or ESI, $\dagger$ Fig. S6 for an enlarged view). The "flipping" behavior is due to the presence of the central pentagon defect while the five pentagons induce negative curvature. For the bowl-to-bowl inversion as illustrated in Fig. 2 $\left(M P M P M \Leftrightarrow \mathrm{TS}_{\text {flip }} \Leftrightarrow M P M P M\right)$, the computed bowl inversion energy of the $\mathrm{C}_{80} \mathrm{H}_{30}$ is $1.7 \mathrm{kcal} \mathrm{mol}^{-1}$, in agreement with the result of ref. 20. However, both $\mathrm{B}_{40} \mathrm{~N}_{40} \mathrm{H}_{30}$ and $\mathrm{Al}_{40} \mathrm{~N}_{40} \mathrm{H}_{30}$ exhibit a deeper bowl structure (see Fig. 1) compared to the warped $\mathrm{C}_{80} \mathrm{H}_{30}$ (with bowl depth $0.37 \AA$ ). Hence, for the $\mathrm{B}_{40} \mathrm{~N}_{40} \mathrm{H}_{30}$ and $\mathrm{Al}_{40} \mathrm{~N}_{40} \mathrm{H}_{30}$ nanoplates, the activation energy of the bowl inversion is 27.9 and $23.2 \mathrm{kcal} \mathrm{mol}^{-1}$, respectively, much higher than that of $\mathrm{C}_{80} \mathrm{H}_{30}$. The $\mathrm{B}_{40} \mathrm{~N}_{40} \mathrm{H}_{30}$ nanoplate possesses the highest bowl inversion energy $\left(27.9 \mathrm{kcal} \mathrm{mol}^{-1}\right.$ ) due also to the strong B-N bonds. A recent study shows that the bowl inversion energy of a chiral nitrogen-doped carbon-bowl reaches an extraordinarily high value of $42.2 \mathrm{kcal} \mathrm{mol}^{-1}$ due largely to the strong $\mathrm{C}-\mathrm{N}$ bonds. ${ }^{26}$

The computed energy barrier for the racemization of the $\mathrm{B}_{40} \mathrm{~N}_{40} \mathrm{H}_{30}$, as shown in Fig. $2\left(M P M P M \Leftrightarrow \mathrm{TS}_{\mathrm{rac}} \Leftrightarrow P M P M P\right)$, is merely $4.3 \mathrm{kcal} \mathrm{mol}^{-1}$, which is much lower than that (18.9 kcal mol ${ }^{-1}$ ) for the $\mathrm{C}_{80} \mathrm{H}_{30}$ nanographene. To simulate

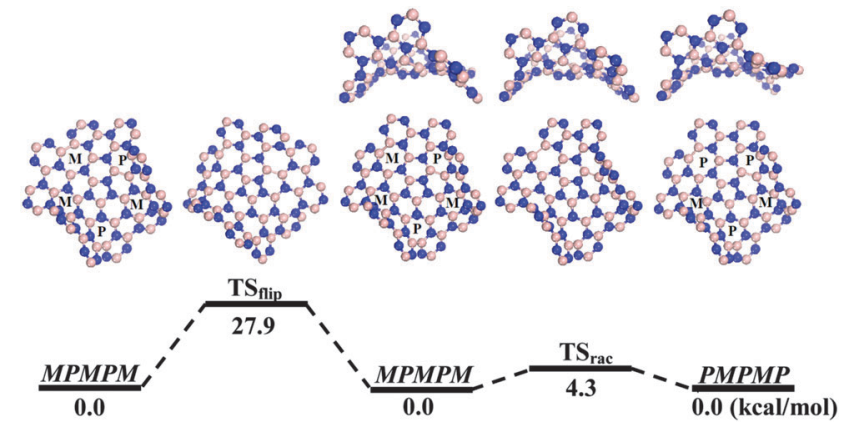

Fig. 2 Bowl-to-bowl inversion (left, MPMPM $\Leftrightarrow \mathrm{TS}_{\text {flip }} \Leftrightarrow M P M P M$ ) and racemization (right, $M P M P M \Leftrightarrow T S_{\text {rac }} \Leftrightarrow P M P M P$ ) pathways for $\mathrm{B}_{40} \mathrm{~N}_{40} \mathrm{H}_{30}$ computed at the B3LYP/6-31G(d) level. All hydrogen atoms at the perimeter are omitted for clarity. Values (in unit of $\mathrm{kcal} \mathrm{mol}^{-1}$ ) are relative Gibbs free energies at $298.15 \mathrm{~K}$ and $1 \mathrm{~atm}$. 


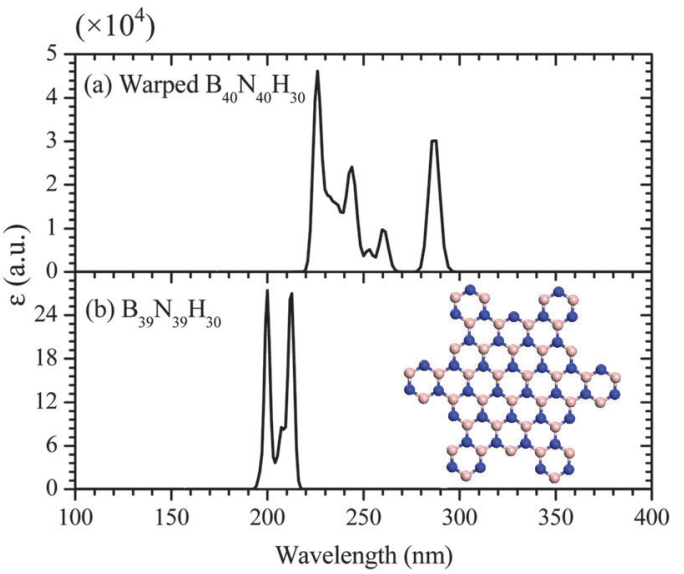

Fig. 3 Computed optical absorption spectra of the (a) warped $\mathrm{B}_{40} \mathrm{~N}_{40} \mathrm{H}_{30}$ and (b) planar $\mathrm{B}_{39} \mathrm{~N}_{39} \mathrm{H}_{30}$ nanoplates with fully BNBN. The planar structure is depicted in the inset of (b), where all hydrogen atoms are omitted for clarity.

the racemization process of the $\mathrm{B}_{40} \mathrm{~N}_{40} \mathrm{H}_{30}$ nanoplate, we perform a Born-Oppenheimer molecular dynamics simulation (see ESI, $\uparrow$ Movie S1) to demonstrate the iterative racemization transitions between the MPMPM and PMPMP enantiomers. For the $\mathrm{Al}_{40} \mathrm{~N}_{40} \mathrm{H}_{30}$ nanoplate, the computed activation energy of racemization is $6.7 \mathrm{kcal} \mathrm{mol}^{-1}$. Hence, both the $\mathrm{B}_{40} \mathrm{~N}_{40} \mathrm{H}_{30}$ and $\mathrm{Al}_{40} \mathrm{~N}_{40} \mathrm{H}_{30}$ nanoplates are expected to exhibit "flapping" motion periodically in solutions.

As expected, the addition of non-hexagonal rings modifies electronic and optical properties of the $\mathrm{B}_{40} \mathrm{~N}_{40} \mathrm{H}_{30}$ and $\mathrm{Al}_{40} \mathrm{~N}_{40} \mathrm{H}_{30}$ Pringles. For example, data for the comparison between the warped $\mathrm{B}_{40} \mathrm{~N}_{40} \mathrm{H}_{30}$ and a planar and fully BNBN alternating $\mathrm{B}_{39} \mathrm{~N}_{39} \mathrm{H}_{30}$ nanoplate (see the inset image in Fig. 3(b)) clearly show that the HOMO-LUMO gap can be appreciably reduced via embedding non-hexagonal rings into the BN nanoplate. The HOMO-energy $\left(E_{\text {Hомо }}=-5.777 \mathrm{eV}\right)$ of the $\mathrm{B}_{40} \mathrm{~N}_{40} \mathrm{H}_{30}$ is shifted upward compared to that of the planar $\mathrm{B}_{39} \mathrm{~N}_{39} \mathrm{H}_{30}\left(E_{\mathrm{HOMO}}=-6.487 \mathrm{eV}\right)$, while the LUMO is shifted downward $\left(E_{\mathrm{LUMO}}=-0.763\right.$ versus $\left.-0.016 \mathrm{eV}\right)$, leading to a narrower HOMO-LUMO gap (5.01 eV) for the warped structure than that $(6.47 \mathrm{eV})$ of the planar $\mathrm{B}_{39} \mathrm{~N}_{39} \mathrm{H}_{30}$. Based on this result, we expect that the introduction of non-hexagonal rings into the BN sheet, a wide-gap semiconductor, can also reduce the bandgap of the BN sheet.

The effect of the non-hexagonal rings on optical properties is illustrated in Fig. 3, where the computed optical absorption spectra of the warped $\mathrm{B}_{40} \mathrm{~N}_{40} \mathrm{H}_{30}$ and the planar $\mathrm{B}_{39} \mathrm{~N}_{39} \mathrm{H}_{30}$ are shown. A major difference between the two spectra is the peaks in the ultraviolet region. The planar $\mathrm{B}_{39} \mathrm{~N}_{39} \mathrm{H}_{30}$ exhibits two sharp peaks at 200 and $213 \mathrm{~nm}$, respectively; the second peak has a shoulder at $207 \mathrm{~nm}$. The spectrum of the warped $\mathrm{B}_{40} \mathrm{~N}_{40} \mathrm{H}_{30}$ exhibits richer features with at least four well-resolved peaks located at 226, 244, 260 , and $288 \mathrm{~nm}$, respectively. Compared to the feature peaks of the planar $\mathrm{B}_{39} \mathrm{~N}_{39} \mathrm{H}_{30}$, the peaks of warped $\mathrm{B}_{40} \mathrm{~N}_{40} \mathrm{H}_{30}$ can be viewed as red-shifted due in part to the narrower HOMO-LUMO gap of the warped structure. These features can be used to differentiate the warped and planar BN nanostructures.

In summary, we investigate structural and electronic properties of warped $\mathrm{B}_{40} \mathrm{~N}_{40} \mathrm{H}_{30}$ and $\mathrm{Al}_{40} \mathrm{~N}_{40} \mathrm{H}_{30}$ nanoplates or Pringles.
Both $\mathrm{B}_{40} \mathrm{~N}_{40} \mathrm{H}_{30}$ and $\mathrm{Al}_{40} \mathrm{~N}_{40} \mathrm{H}_{30}$ nanoplates are local minima on the potential energy surfaces without imaginary frequencies. Compared to the $\mathrm{C}_{80} \mathrm{H}_{30}$ counterpart, the $\mathrm{B}_{40} \mathrm{~N}_{40} \mathrm{H}_{30}$ and $\mathrm{Al}_{40} \mathrm{~N}_{40} \mathrm{H}_{30}$ nanoplates have much higher bowl inversion energy due to their deeper bowl depth and relatively stronger chemical bonds $\mathrm{B}-\mathrm{N}$ (or Al-N) bonds. More interestingly, the $\mathrm{B}_{40} \mathrm{~N}_{40} \mathrm{H}_{30}$ and $\mathrm{Al}_{40} \mathrm{~N}_{40} \mathrm{H}_{30}$ nanoplates are expected to exhibit "flapping" motion in solution due to the much lower energy barrier of the racemization compared to that of the $\mathrm{C}_{80} \mathrm{H}_{30}$ counterpart. Finally, embedding nonhexagonal rings in BN nanoplates can reduce the HOMO-LUMO gap. Such a bandgap-reduction by introduction of non-hexagonal rings can exploit electronic properties of BN nanostructures for nanoelectronic applications.

WF acknowledges the State Scholarship Fund provided by the China Scholarship Council through No. 201308320156. XCZ is supported by ARL (Grant No. W911NF1020099), NSF (Grant No. DMR-0820521), and UNL Holland Computing Center, and a grant from USTC for (1000 Talents Plan) summer research.

\section{Notes and references}

1 H. W. Kroto, J. R. Heath, S. C. O'Brien, R. F. Curl and R. E. Smalley, Nature, 1985, 318, 162-163.

2 S. Iijima, Nature, 1991, 354, 56-58.

3 K. S. Novoselov, A. K. Geim, S. V. Morozov, D. Jiang, Y. Zhang, S. V. Dubonos, I. V. Girgorieva and A. A. Firsov, Science, 2004, 306, 666-669.

4 N. G. Chopra, R. J. Luyken, K. Cherrey, V. H. Crespi, M. L. Cohen, S. G. Louie and A. Zettl, Science, 1995, 269, 966-967.

5 W. Mickelson, S. Aloni, W. Q. Han, J. Cumings and A. Zettl, Science, 2003, 300, 467-469.

6 A. Loiseau, F. Willaime, N. Demoncy, G. Hug and H. Pascard, Phys. Rev. Lett., 1996, 76, 4737-4740.

7 X. Xia, D. A. Jelski, J. R. Bowser and T. F. George, J. Am. Chem. Soc., 1992, 114, 6493-6496.

8 F. Jensen, Chem. Phys. Lett., 1993, 209, 417-422.

9 D. L. Strout, J. Phys. Chem. A, 2001, 105, 261-263.

10 M. Monajjemi and J. E. Boggs, J. Phys. Chem. A, 2013, 117, 1670-1684.

11 Y. B. Zhang, Y. W. Tan, H. L. Stormer and P. Kim, Nature, 2005, 438, 201-204.

12 K. S. Novoselov, D. Jiang, F. Schedin, T. J. Booth, V. V. Khotkevich, S. V. Morozov and A. K. Geim, Proc. Natl. Acad. Sci. U. S. A., 2005, 102, 10451-10453.

13 A. Nag, K. Raidongia, K. P. S. S. Hembram, R. Datta, U. V. Waghmare and C. N. R. Rao, ACS Nano, 2010, 4, 1539-1544.

14 D. Golberg, Y. Bando, Y. Huang, T. Terao, M. Mitome, C. Tang and C. Zhi, ACS Nano, 2010, 4, 2979-2993.

15 F. Jensen and H. Toftlund, Chem. Phys. Lett., 1993, 201, 89-96.

16 H. Y. Zhu, T. G. Schmalz and D. J. Klein, Int. J. Quantum Chem., 1997, 63, 393-401.

17 W. Auwärter, M. Muntwiler, J. Osterwalder and T. Greber, Surf. Sci., 2003, 545, L735-L740.

18 X. Li, X. Wu, X. C. Zeng and J. Yang, ACS Nano, 2012, 6, 4104-4112.

19 S. S. Yamijala and S. K. Pati, J. Phys. Chem. C, 2013, 117, 3580-3594.

20 K. Kawasumi, Q. Zhang, Y. Segawa, L. T. Scott and K. Itami, Nat. Chem., 2013, 5, 739-744.

21 C. Liu, Z. Hu, Q. Wu, X. Wang, Y. Chen, H. Sang, J. Zhu, S. Deng and N. Xu, J. Am. Chem. Soc., 2005, 127, 1318-1322.

22 X. H. Ji, S. P. Lau, S. F. Yu, H. Y. Yang, T. S. Herng, A. Sedhain, J. Y. Lin, H. X. Jiang, K. S. Teng and J. S. Chen, Appl. Phys. Lett., 2007, 90, 193118.

23 H. Wang, Z. Xie, Y. Wang, W. Yang, Q. Zeng, F. Xing and L. An, Nanotechnology, 2009, 20, 025611.

24 Y. Mei, D. J. Thurmer, C. Deneke, S. Kiravittaya, Y. F. Chen, A. Dadgar, F. Bertram, B. Baster, A. Krost, J. Christen, T. Reindl, M. Stoffel, E. Coric and O. G. Schmidt, ACS Nano, 2009, 3, 1663-1668.

25 P. J. Jessup and J. A. Reiss, Aust. J. Chem., 1976, 29, 173-176.

26 Q. Tan, S. Higashibayashi, S. Karanjit and H. Sakurai, Nat. Commun., $2012,3,891$. 